\title{
Geographical information systems in health research and services delivery in the Philippines
}

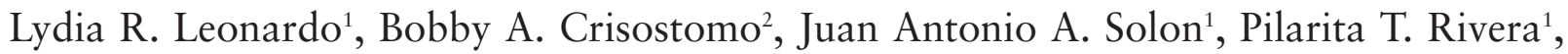 \\ Alvin B. Marcelo ${ }^{3}$, Jonathan M. Villasper ${ }^{3}$ \\ ${ }^{1}$ Department of Parasitology, College of Public Health University of the Philippines, Manila, the \\ Philippines; ${ }^{2}$ National Mapping and Resource Information Authority, Manila, the Philippines; ${ }^{3}$ National \\ Telehealth Center, University of the Philippines, Manila, the Philippines; ${ }^{4}$ Department of Geography, \\ College of Social Sciences and Philosophy, University of the Philippines, Diliman, the Philippines
}

\begin{abstract}
Accessible public data emanating from remote sensing from earth-observing satellites, as well as geographical information systems in general, are playing an increasing role in the public health sector in the Philippines. This paper reviews currently available systems in the country in this area, emphasizing the utility in complementing field studies with the development of disease models. The goal is to map out important biological threats by characterizing the niches infectious agents, and their vectors or intermediate hosts, occupy temporally and spatially.
\end{abstract}

Keywords: The Philippines, geographical information system, remote sensing, epidemiology, mapping, public health, health service, health delivery.

\section{Introduction}

Geographical information systems (GIS) and remote sensing (RS) are the latest technologies added to man's growing arsenal in the fight against age-old and emerging diseases. Originally developed for military reconnaissance, these technologies have rapidly found use in areas as diverse as meteorology, oceanography, forestry, urban development and ecology. Geospatial applications have also been appropriated by the medical field where they are not only used for general information management for the health services but have also been developed into powerful tools revolutionizing the way epidemiological research is carried out.

Before being supported by sensor data from

Corresponding author:

Lydia R. Leonardo

Department of Parasitology

College of Public Health University of the Philippines

Manila, the Philippines

Tel. +6325325929 Fax +632521 1394

E-mail: lydiar12002@yahoo.com satellites, advanced image-analyses and statistical methods, the relationships between agro-climatic data, disease prevalence and vector distribution could neither easily be shown, nor comprehensively understood and studied. The situation now is quite different.

Never before has the epidemiological background of diseases with environmental determinants been so clearly exposed, not only making it possible to identify their exact prevalence distribution but also pinpointing areas where the conditions are supportive for certain endemic hazards, parasitic infections in particular. Clearly, such information is of great importance as it facilitates geographic localization and time projection when the risk for disease outbreaks would be at critical levels. The data emanating from current RS/GIS activities, regularly furnished by epidemiologists and scientists specializing in the study of ecosystems, complement ongoing field studies and facilitate the generation of near real-time map reports.

This paper presents how GIS has been utilized in health research in the Philippines and how it is 
explored as a tool to improve the health services delivery system.

\section{General GIS activities in the Philippines}

As in many countries in the West where RS is currently used, the introduction of this technology in the Philippines in the mid-1970s was primarily for the purpose of generating baseline resource information as well as for monitoring and inventory assessment of forest, mineral and coastal-zone resources. An early successful RS application was the inventory of all forested areas in the Philippines conducted by the Department of Environment and Natural Resources using the General Electric Image 100 system to process US LandSat MSS scenes taken between 1972 and 1976 (Solis, 1992).

In 1974, multi-disciplinary researchers from the University of the Philippines (UP) developed the first prototype computerized GIS model in the country dealing with a computerized land assessment and planning system. This model was eventually introduced into several government agencies in 1979. The increased use of GIS started just about this decade focusing on land use and environmental assessment.

Since then, the use of these new technologies in meteorology, positioning and navigation, communications and scientific research has grown substantially in extent and magnitude finally pervading so many areas of the government that it necessitated the creation of an inter-agency body, i.e. the Science and Technology Coordinating Council - Committee for Space Technology Application (STCC-COSTA), which has the mandate to serve as the national body coordinating and overseeing all activities related to space technology (Fajardo et al., 2001).

Four government agencies are credited with having played key roles in the unprecedented growth of RS and GIS in the Philippines in the 1990s. These are the National Mapping and Resource Information Authority (NAMRIA), the Philippine Atmospheric Geophysical and Astronomical Services Administration (PAGASA), the Soils Research Development Center (SRDC) - Bureau of Soils and Water Management (BSWM) and the UP Training Center for Applied Geodesy and Photogrammetry (UPTCAGP) (Papa, 2003).

Table 1. Current availability of GIS capabilities at different levels in the Philippines.

\begin{tabular}{lcccccccc}
\hline \multirow{2}{*}{$\begin{array}{l}\text { Local government units } \\
\text { (LGUs) }\end{array}$} & \multicolumn{2}{c}{ Municipalities } & \multicolumn{2}{c}{ Cities } & \multicolumn{2}{c}{ Provinces } & \multicolumn{2}{c}{ Total } \\
\cline { 2 - 8 } & No. & $\%$ & No. & $\%$ & No. & $\%$ & No. & $\%$ \\
\hline With GIS capability & 215 & 14 & 71 & 61 & 42 & 53 & 328 \\
Without any GIS & 1285 & 86 & 46 & 39 & 37 & 47 & 1368 & 81 \\
Total no. of LGUs & 1500 & 100 & 117 & 100 & 79 & 100 & 1696 \\
\hline
\end{tabular}

Table 2. Diversity of GIS capabilities at the different levels of local government units (LGUs) in the Philippines.

\begin{tabular}{|c|c|c|c|c|c|c|c|c|}
\hline \multirow{2}{*}{$\begin{array}{l}\text { Level of GIS } \\
\text { capability }\end{array}$} & \multicolumn{2}{|c|}{ Municipalities } & \multicolumn{2}{|c|}{ Cities } & \multicolumn{2}{|c|}{ Provinces } & \multicolumn{2}{|c|}{ Total } \\
\hline & No. & $\%$ & No. & $\%$ & No. & $\%$ & No. & $\%$ \\
\hline Acquaintance & 1285 & 86 & 46 & 39 & 37 & 47 & 1368 & 81 \\
\hline Gestational & 175 & 12 & 35 & 30 & 20 & 25 & 230 & 14 \\
\hline Developmental & 35 & 2 & 23 & 20 & 18 & 23 & 76 & 4 \\
\hline Operational & 5 & 0 & 13 & 11 & 4 & 5 & 22 & 1 \\
\hline Total no. of LGUs & 1500 & 100 & 117 & 100 & 79 & 100 & 1696 & 100 \\
\hline
\end{tabular}


The results of a nationwide survey of GIS capabilities of local government units (LGUs) conducted in the years 2001 - 2003 by NAMRIA showed that the majority of these political and geographical entities had only reached the very early stage of GIS development, e.g. acquaintance and the gestation stages (Tables 1 and 2). Efforts to improve GIS capability were then intensified as the new technology's invaluable contribution to decision-making was realized and its advantages in facilitating various development activities became evident. The Department of Health (DOH) initiated several GIS projects based on the promise of this technology in health planning and disease surveillance (Inventory, 2004).

\section{GIS capabilities at key government health-related institutions}

Faced with the dearth of written documentation of GIS-based health projects, its use in health research and how it has been explored as a tool to improve the delivery of health services, a computer search was carried out using a general-purpose search engine <www.google.com> and the more narrow search engine for medical research papers and communications <www.pubmed.com > together with visits to special websites known to the team of authors such as <www.doh.gov.ph>, <www.gisdevelopment.com> and <www.geocomm.com>. In addition, $\mathrm{DOH}$ officials, involved in the said projects, were interviewed and an informal listing produced by technical personnel assigned to compile lists of GIS projects in the DOH was consulted. Further, proceedings of a conference on GIS use and potential, sponsored by the UP Health Informatics Unit, headed by one of the authors of this paper, provided information on the capabilities of some provinces or LGUs with reference to this technology. Finally, a review of annual reports of NAMRIA revealed the overall state of GIS utilization in the country.

Besides the $\mathrm{DOH}$, the major institutions for health in the Philippines include the Research Institute for
Tropical Medicine (RITM), the UP Manila and the Philippine Council for Health Research and Development (PCHRD). The mandates of these institutions are as follows:

(i) the $\mathrm{DOH}$ is the principal health agency in the Philippines and is responsible for ensuring access to basic public health services to all Philippinos through the provision of quality health care and regulation of providers of health goods and services <http://www. doh.gov.ph/profile.htm>;

(ii) the RITM is a research facility under the $\mathrm{DOH}$ which was formally established in 1981 with the signing of Executive Order No. 674. It is responsible for planning and implementing research programmes for infectious and/or tropical diseases <http://www.ritm.gov.ph/abt.htm>;

(iii) the UP Manila is one of the seven autonomous universities under the UP system and is an education center for health sciences and research <http://www.upm.edu.ph/aboutupm/ aboutupm-overview.htm>. It has two health units which are centers of excellence: (a) the National Institutes of Health - Philippines (NIHPhilippines) which is a recognized authority on health research and development in the country and is a key source of critical health information for national development in the Philippines and Southeast Asia <http://www.iamp-online.org/ interacademy-networ-to-monitor-emerginginfections>; and (b) the Philippine General Hospital which is the premier tertiary hospital continuing to uphold its mission of providing health care, training, research and quality health service, particularly to the underprivileged. It is a center of excellence and leadership with a strong impact on health policies <http://www.pgh.gov.ph/v2/?fid=aboutus>.

The PCHRD is one of five sector councils of the Department of Science and Technology (DOST), a forward-looking, partnership-based national body responsible for coordinating and monitoring all activities in the field of research and development with reference to health at the national level 
<http://www.pchrd.dost.gov.ph/newpchrd/index. php?option=com_content $\&$ task=view $\&$ id $=34 \&$ Ite $\operatorname{mid}=33>$.

All these key institutions, with the exception of the PCHRD, which acts only as a coordinating and monitoring body, have either established a GIS laboratory or undertaken a GIS health project.

\section{Applications}

With support from the Asian Development Bank (ADB), the Maternal GIS Project was initiated under the Women's Health and Safe Motherhood Programme in December 1999. It was conducted in collaboration with NAMRIA developing the following three components:

(i) the National Health Atlas, the aim of which was to develop an integrated GIS database of health facilities, i.e. a tool to display the locations of 2,410 rural health units (RHUs) and 690 public hospitals in the country and facilitate the retrieval of information for any upcoming queries in this field. The location of the RHUs and hospitals was recorded through a ground survey using hand-held global positioning system (GPS) devices. However, all forms, distributed to these health facilities to gather data for the database, were not returned and the database "only" contains information from 1,878 RHUs and 446 hospitals. Although the survey was not completed the National Health Atlas is still useful. It can be accessed at the DOH website <http://www.doh.gov.ph/ databases.htm>;

(ii) the Maternal Health Modeling is a GIS-based application system and a model to gauge the effect of project inputs (materials, supplies and services) provided by the different health facilities on maternal health. The following indicators were used by the model: pre-natal attendance, post-natal attendance, maternal and infant mortality rate, and birth weight. Factors or variables that have significant influence on these indicators were analyzed and identified. These include the catchment population, the number of health workers, the facility age, the length of clinic hours, available equipment, drugs/medicines and supplies, accessibility of the health facility, etc. The model was designed to also be able to use spatial data analysis with regard to location/allocation in order to identify the demands of the catchment population, which would show which health facilities require assistance. The pilot areas chosen for this component were Capiz, a province in the Visayas region, and Mt. Province in Luzon; and (iii) the Maternal Health GIS Laboratory at the National Epidemiology Center (NEC) at the Philippine Department of Health.

The investigation of a system for the analysis of the utilization of support to different health facilities was carried out as a pilot study. This was also done in Capiz where the Maternal Health Modeling study took place. Another pilot study, aimed to set up an Infectious Disease Data Management System, was conducted in three municipalities in Cavite in Metro Manila covering two diseases, namely rabies and pulmonary tuberculosis. Apart from the major projects described above, which were supported by both national and foreign donors, the various programmes at the $\mathrm{DOH}$ have made efforts to incorporate GIS-based methodologies in their operation and service, both for small and more far-reaching activities. The National Epidemiology Center, which is responsible for regular surveillance and disease monitoring, is gradually shifting to more powerful visualization and analysis tools in performing its obligations. Various sections in the $\mathrm{DOH}$ in charge of control and prevention of different diseases in the country are also slowly turning to GIS as way to determine the magnitude and extent of disease problems. For example, the RITM used GIS in a fiveyear project funded by the NIH in the United States entitled "Schistosomiasis transmission and ecology in the Philippines".

Interfacing agriculture and health, the Food and Agriculture Organization (FAO) launched an inter- 
national initiative with reference to food, i.e. the Food Insecurity and Vulnerability Information Mapping System (FIVIMS). The Philippine component is managed by the National Nutrition Council, a policy-making body composed of key government agencies and private sector representatives. The group identified 12 variables and, using regression and cluster analysis, categorized the provinces of the Philippines into five vulnerability clusters ranging from not vulnerable to highly vulnerable. In order to make this large body of data more accessible to policy planners it has been produced in the form of maps. In this way, the project, accessible at the $<$ http://www.asiafivims.net/phil/phi_web2/PH2\%20 1-1.html> website, has provided the decision makers at the national level with the advantage of summarizing priorities. Although it is not inconceivable that "highly vulnerable" villages exist in provinces that are not classified as such, there are no data to identify vulnerable areas in the lower political units (municipalities or cities).

The first successful attempt of using RS and GIS in health research was a study, carried out by UP Manila, applying these technologies in determining the environmental determinants of the two vectorborne diseases, i.e. malaria and schistosomiasis (Leonardo et al., 2005). The programmes developed in the project were turned over to the pilot municipalities in Davao del Norte in Mindanao for updating of prevalence maps and other data collected during the duration of the study. A seminar held to facilitate the dissemination of the information collected served as an eye-opener for what GIS can do by attracting many municipal health officers and other information technology personnel. In fact, the success of this study encouraged another faculty in UP Manila where Dr. Pilarita Rivera proposed to extend the coverage to the national level concentrating on the most important of diseases, e.g. malaria. The project entitled "Application of GIS in malaria surveillance in disaster-prone provinces in the Philippines" will produce malaria GIS maps which will be regularly updated and used in the evaluation of the effectiveness of the local malaria control programmes. The maps will no doubt find good use in strategic planning for malaria control at the local level, in budget planning and prioritization of local resources, in developing malaria information and advisory packages for local residents and foreign travelers, malaria risk assessment at the national level and in recommendation of policy and programmatic measures to enable the malaria control programme in responding and managing malaria during disasters and other emergencies (Bloland and Williams, 2001). A comparative analysis of the topographic factors and their relationship with prevalence of malaria in various areas with different environmental and climatic conditions was also performed.

Among the LGUs, some provinces in the Visayas region and the Pangasinan province in Luzon have started turning to GIS as a means of improving their services in general. The provincial government of Capiz depends much on GIS in the area of health provision and it has one of the strongest transmitters in the country. The data are collected by the Bisita sa Pamilya programme, stored in the MS Access database <www.microsoft.com> and software programming is done with Borland $\mathrm{C}++$ and displayed using ArcView 3.1. Health officials access the GIS-based tools to contact candidates for surgical missions such as, for example, Operation Smile (a surgical mission for cleft lip and cleft palate patients). Patients with congenital face deformities used to be recruited for operation in an ad hoc manner but GIS permits a fairer and more straightforward selection from the database. Other examples of local use of GIS include the tracking of dengue cases and selection of candidates for the indigent programme of the Philippine Health Insurance Corporation.

Cebu city in the province of the same name has a GIS center which supports other city government departments in the management of their projects and in the improvement of their services. In Luzon, the Pangasinan provincial government started the use of GIS to map out, in ten pilot municipalities, the service delivery points (SDP) which include 
RHUs, hospitals, private clinics and pharmacies, and reproductive health indicators. The objective is to develop a system leading to a referral process that will direct users of the family planning programme to the appropriate SDP not only depending on their needs of commodities and requirements in this area but also on their capacity to pay. The activity is at present housed in the Provincial Population Office. It employs non-customized ArcView 3.3 with the network analyst extension for production of the maps which depict the road networks and barangay (village) boundaries based on land use maps of the various municipalities and data provided by the Land Management Bureau and NAMRIA. An expanded follow-up project has been subsequently developed that is expected to be funded by USAID.

The Philippine Institute for Development Studies (PIDS) launched a GIS-based website of socio-economic indicators <www.pids.gov.ph> at the regional and provincial levels. However, only two health indicators, infant mortality rate and prevalence of malnutrition, were featured in this undertaking.

The Inter-agency Task Force on Geographic Information (IATFGI) was created on 15 April 1993 by virtue of the National Statistical Coordination Board (NSCB) Memorandum Order No. 01-93. The IATFGI is primarily in charge of promotion and coordination of the efficient development, management and utilization of geographic information in the Philippines. NAMRIA acts as the chair and NSCB as the co-chair of IATFGI. The only IATFGI member-agency engaged in health services is $\mathrm{DOH}$ which acts as the Chair of the IATFGI's technical working group (TWG) on socio-economics and has become very active in the IATFGI's standardisation activities. The TWG on Socio-Economics is respon- sible for the development of standards in the creation and use of all major geographic information holdings for socio-economic activities such as population, income, mortality, and health facilities (Milrad, 1990).

Most, if not all, of these GIS projects make use of personal computers, mostly pentium-based. Peripherals include digitizers, plotters and scanners. The GIS software products used are Arc/Info and ArcView.

Efforts to standardize the documentation of GIS data in the health area

All GIS applications customized for the maternal GIS project employ a standard coding scheme which was developed to uniquely identify all the RHUs and hospitals encoded in the areas covered by the system. The coding scheme was given the name HF_CODE which is short for "Health Facility Code". The same scheme was adopted for the development of the Philippine database in Health Mapper, which is a surveillance and mapping system for infectious diseases developed by the World Health Organization (WHO) and the United Nations International Children's Emergency Fund (UNICEF) < http://www.who.int/health_mapping/ tools/healthmapper/en/index.html>. Its structure is composed of three levels: the Philippine standard geographic code (PSGC) component, the facility type and a facility number, as shown in Table 3.

The first level is the 6-digit PSGC code developed by the National Statistics Coordination Board (NSCB) which is a systematic classification of geographic areas in the Philippines. This classification is

Table 3. Example of how the geographical location and type of facility for health-delivery are used to construct a standard code for use in health databases in the Philippines.

\begin{tabular}{lccl}
\hline PSGC component & Type & Facility no. & Administrative unit/geographical location \\
\hline 061903 & $\mathrm{R}$ & 0001 & Dumalag RHU \\
061904 & $\mathrm{H}$ & 0001 & Dumaro Medicare Community Hospital \\
\hline
\end{tabular}


based on the three well-established levels of geographical-political subdivisions of the country such as the region, the province, and the municipality/city. The PSGC is being adopted as a standard code by the IATFGI and used by NAMRIA in most of its GIS development projects. The second level of the HF_CODE identifies the type of health facility where ' $H$ ' stands for hospital and ' $R$ ' for RHU. The facility number, finally, is a four-digit sequential number that defines the health facility within that municipality. As an illustration, an RHU with a facility number '0003' means that it is the third RHU (in sequence) within that municipality. The default value is '0001' (Papa and Crisostomo, 2003).

\section{Issues and prospects for the future}

The challenges that come with introducing a radically new technology that changes existing procedures completely are always great. The start-up cost of establishing the new GIS technology in terms of hardware and software, manpower training and maintenance is tremendously high and most pioneers in a situation like this must therefore have access to special funds which in practice means that they will have to rely on foreign donors such as the World Bank, USAID, WHO, etc. The huge cash flow needed for the acquisition of hardware and software could be overwhelming to an agency new to the field.

Due to security reasons and the requirement of continuing maintenance, most of this expensive GIS equipment and software are kept in offices of highranking officials where access necessarily becomes limited. This situation discourages trained personnel from practicing what they have been trained to do resulting in underused equipment and underdeveloped GIS facilities.

Staff is faced with many problems in implementing GIS technology such as funding and updating of the GIS databases, integrating data with other information systems and maintenance. Regarding the data itself there is not only the need of determining the availability and accuracy of specific datasets, but also the problem of obtaining specific, timely data in a desired map scale and projection and getting access to the right storage medium. In addition, the end-user must know all about data conversion, translation of files, have experience with large datasets and be security-minded. Finally, it would not be possible to work in this field without good cooperation with those who produce the data and the unfailing support of management and vendors (Yavas et al., 1985).

The experience proves that the start-up of a GIS project is much less of a problem than to sustain the activities encouraged. The task of moving on with minimal financial support, or none at all, becomes daunting after the final project reports have been turned in and the huge responsibility of carrying on without further support sinks in. The personnel working within the framework of a GIS project mostly have background knowledge in the area of information technology (or in adjacent fields such as geodetic engineering and geography) or have undergone special training in GIS through a course taken locally or abroad. When the projects terminate, the staff is either absorbed by departments with similar projects, return to their original appointments or leave altogether to seek other employments. Postproject stagnation is a potentially serious problem that must be tackled without delay as there generally is a lack of ideas on how and where to use the equipment caused by low or missing incentive coupled with poor encouragement to use the technology for new projects. Added to this is the impression of GIS as a novelty or a fad which every office must have and which might be replaced by something else in a few years time. Hence, the risk is great that the equipment ends up in a showroom untouched or under-used in offices which have no real need for it.

In spite of the considerable problems that the information revolution brings with it, there is no doubt that the role of GIS in health research and services delivery in the Philippines is wellentrenched. The efforts of the government in coor- 
dinating and supporting GIS initiatives in the various sectors are a source of encouragement. The direction of activities and the objective of the $\mathrm{DOH}$ in using GIS for evidence-based planning, monitoring, evaluation, and policy-making activities assure stakeholders of the sustainability of the systems employed (National Objectives for Health, 1999). Attempts to make GIS technology available to the public with efforts such as offer free downloading of the powerful GRASS software package not only turn on the green light for late starters but facilitate the work for those who have already made a head start. In addition, several websites offer public access data at different scales from the global level down to regional and provincial levels.

Significant sites offering free data are the Digital Chart of the World at <www.maproom.psu.edu/dcw/>, the University of Maryland (UM)'s highly empowered "Global Land Cover Facility (GLCF)" at <http://glcf.umiacs.umd.edu/index.shtml>, and the National Aeronautics and Space Administration's "World Wind" at the <http://www.worldwind. arc.nasa.gov/index.html> website. The GLCF archive offers raw satellite images of almost any place on the earth that can be downloaded for free. The images are donations to, and holdings of, the UM that have been released for public consumption. The Philippines is well covered by their LandSat holdings. On the other hand, World Wind provides a technology for viewing the earth's terrain in visually rich 3D and for virtually visiting any place in the world. LandSat imagery and Shuttle Radar Topography Mission (SRTM) elevation data are used to be able to fly across the world including the Philippines in any direction. World Wind makes available also the Moderate Resolution Imaging Spectroradiometer (MODIS) data covering the Philippines for viewing and downloading. The "Google Earth" which is available at the Google website <http://earth.google.com/index.html> has features very similar to those of World Wind. However, some of its data cannot be downloaded for free but for a fee.

\section{Conclusions}

The cost for a country to equip itself and making itself ready to join the global mainstream of GIS users is very high. However, the potential profits are equally high and for a country whose main resource is its people, GIS may be crucial in the quest towards improved health and welfare.

The decision to set up a centralized separate GIS department or designate fulltime and permanent GIS personnel is not far-fetched. However, sustainability is the key and will depend critically on the technical know-how as well as upgrading of skills, either through formal degree programmes or through short courses; even training to use specific software packages. This certainly reduces the expenses for hiring foreign consultants, something that could not be avoided in the early days of starting up GIS activities from scratch.

GIS applications in the area of public health have brought in a new wave of optimism in this sector regarding the way health-oriented research and delivery of services will develop. Convinced of the power and facility which this tool can provide for information management, both administration and rank and file of the Philippine DOH have expressed willingness to overhaul the existing system and move to formats compatible with this technology. Outside the government, in the academe, the private sector and among non-governmental organizations, GIS is slowly becoming an essential tool in many of their activities, both in research and in the delivery of services.

\section{References}

Bloland PB, Williams HA, 2001. Malaria control during mass population movements and natural disasters. Washington, DC, National Academies Press.

Fajardo IS, Carandang E, Crisostomo BA, 2000. Country report on space satellite projects and policy in the Philippines.

Inventory of the Status of GIS Capabilities of Local Government Units, 2004. Information management department, national mapping \& resource information authority (NAMRIA).

Leonardo LR, Rivera PT, Crisostomo BA, Sarol JN, Bantayan 
NC, Tiu WU, Bergquist NR, 2005. A study of the environmental determinants of malaria and schistosomiasis in the Philippines using remote sensing and geographic information systems. Parassitologia 47, 105-114.

Milrad L, 1990. Multiparticipant GIS projects - some legal issues. GIS for the 1990s Conference Proceedings, 994-1000.

National Objectives for Health (Philippines 1999-2004), 1999, Department of Health.

Papa LSD, 2003. Growing use of GIS in the Philippines and professionalizing GIS practice in government. Paper presented during the UP-NCPAG Discussion/Workshop.

Papa LSD, Crisostomo BA, 2003. The establishment of a technical, operational and legal framework for the management of geographic information in the Philippines. Presented at the $8^{\text {th }}$ National Convention on Statistics, Westin Philippine Plaza.

Solis JG, 1992. Country report on remote sensing and GIS activities in the Philippines.

Yavas U, Kaynak E, Dilber M, 1985. The managerial climate in less developed countries. Manag Dec 23, 29-40.

Websites for further information about activities and institutions mentioned

Department of Health. 7 Dec. 2005. 28 Apr. 2006 <http://www.doh.gov.ph/profile.htm>.

Digital Chart of the World Data Server. 25 May 2005. 28 Apr 2006. <www.maproom.psu.edu/dcw/>.

Food Insecurity and Vulnerability Information Mapping System (FIVIMS) for the Philippines. 2006. 28 Apr. 2006 <http://www.asiafivims.net/phil/phi_web-2/PH2\%2011.html>.

GeoCommunity - the Premier Portal for Geospatial
Technology Professionals. 2005. 28 Apr. 2006 < http://www.geocomm.com/>.

GIS development. 2006. 28 Apr. 2006 < http://www.gisdevelopment.com>.

Global Land Cover Facility. 2006. 28 Apr. 2006 $<$ http://glcf.umiacs.umd.edu/index.shtml>.

Google Earth. 2006. 29 Dec. 2006. <http://earth.google. com/index.html>.

International Academy Medical Panel. 2006. 28 Apr. 2006 <http://www.iamp-online.org/interacademy-networ-tomonitor-emerging-infections $>$.

National Aeronatics and Space Administration (NASA) World Wind 1.4. 16 Oct. 2006. 29 Dec. 2006. <http:// www.worldwind.arc.nasa.gov/index.html>.

National Institutes of Health (NIH) - Health literature search. 2006. 28 Apr. 2006 <http://www.ncbi.nlm.nih.gov /entrez/query.fcgi?DB=pubmed $>$.

Philippine Council for Health Research and Development. 2006. 28 Apr. 2006 <http://www.pchrd.dost.gov.ph/new$\mathrm{pchrd} / \mathrm{index}$.php? option $=$ com_content $\&$ task $=$ view \&id $=34 \&$ Itemid $=33>$.

Philippine General Hospital. 2004. 28 Apr. 2006 <http://www.pgh.gov.ph/v2/?fid=aboutus $>$.

Philippine Institute for Development Studies. 2006. 28 Apr. 2006 <http://www.pids.gov.ph/>.

Research Institute for Tropical Medicine. 23 Feb. 2006. 28 Apr. 2006 <http://www.ritm.gov.ph/abt.htm>.

University of the Philippines Manila. 2002. 28 Apr. 2006. <http://www.upm.edu.ph/aboutupm/aboutupmoverview.htm>.

World Health Organization (WHO) - Public Health Mapping. 2006. 28 Apr 2006. <http://www.who.int/ health_mapping/tools/healthmapper/en/index.html>. 